\title{
Convergence Clustering of the Chinese Provinces: New Evidence from Several Macroeconomic Indicators
}

\begin{abstract}
In this paper, the convergence clustering in 31 Chinese provinces regarding several important economic indicators over the period 1952-2013 was empirically investigated. Several provincial clusters were identified in the per capita (real) gross domestic product (GDP), consumption-income ratio, retail price-, and consumer price inflation rates, using the club convergence and clustering procedure of Phillips and Sul (2007). The empirical findings are as follows: First, it was found that all series of the original data contain a significant nonlinear component. Second, it was observed that there are five significant clusters for the per capita income in China. Third, it was found that there are four significant clusters for the consumption income ratio. Fourth, it was observed that there are four significant clusters for the retail inflation rates, and two significant clusters for the consumer inflation rates in China. These results will enable local and central planners to implement economic growth, savings and price adjustment policies for different groups of provinces.
\end{abstract}

Keywords: Regional economic activity; regional inflation; nonlinearity; convergence clustering; spatial distributions; Chinese economy.

JEL Classification Codes: R11; R12; C23

\section{Introduction}

Convergence clustering in 31 Chinese provinces regarding several important economic indicators over the period 1952-2013 was empirically investigated in this paper. Several provincial clusters were identified in the per capita (real) gross 
domestic product $(\mathrm{GDP})$, consumption-income ratio $(\mathrm{C} / \mathrm{Y})$, retail price, and consumer price inflation rates, using the club convergence and clustering procedure of Phillips and Sul (2007). The main advantage of the method of Phillips and Sul (2007) is that it takes heterogeneity into account across the Chinese regions within a nonlinear time-varying framework.

Indeed, it is important to investigate the convergence clustering of Chinese provinces with regards to economic indicators. One of the stylized facts in the literature is that the income inequality in Chinese provinces has increased (divergence across provinces) since 1979, due to the significant institutional reform in 1979 (Cheong and $\mathrm{Wu}, 2013,2014$; Ho and Li, 2010; Knight, 2014; Lau, 2010; Lyhagen and Rickne, 2014). For instance, Ho and Li (2010) investigated the stochastic properties of output per capita across the Chinese provinces for the period 1984 to 2003, and observed the significant evidence of output divergence across the provinces. Similar evidence was obtained by Lyhagen and Rickne (2014) for half of Chinese cities by using the nonlinear trend functions in the vector error correction model (VECM) over the period 1952-2007.

However, there are also many papers in the literature that show evidence of the convergence of per capita income (output) across the Chinese provinces (Herrerias and Ordonez, 2012; Herrerias and Ordonez Monfort, 2015; Herrerias et al., 2011; 
Sakamoto and Islam, 2008). For instance, Herrerias et al. (2011) obtained the evidence of convergence for the per capita GDP across 28 Chinese provinces for the period 1952 to 2005. Using the method of Phillips and Sul (2007), Herrerias and Ordonez (2012) investigated the stochastic properties of club convergence in terms of per capita income, labor productivity and capital intensity for the period 1952 to 2008. They found a statistically significant club convergence in the Chinese regions over the period under study. Herrerias and Ordonez Monfort (2015) also investigated the stochastic properties of convergence across 28 Chinese provinces for the period 1952 to 2008, using the test technique of Phillips and Sul (2007). They observed a significant degree of convergence in capital intensity, labor productivity and total factor productivity (TFP) in the Chinese provinces. Shortly, there are two empirical results with regards to the stochastic properties of the per capita income across Chinese provinces. First, scholars found a significant divergence across the Chinese provinces. Second, scholars observed a non-linear club convergence across the Chinese provinces. The findings of the current study are in line with one of these two results (the latter in our case).

In addition, the empirical results of the consumption-income $(\mathrm{C} / \mathrm{Y})$ ratio can be used in macro-econometric modelling and policy implications for the understanding of consumption function (therefore savings behavior) as well as global imbalances, due to the significant and increasing share of the Chinese economy in the world economy. For instance, Chow $(1985,2010,2011,2016)$ obtained evidence in favor of the permanent income hypothesis (PIH) of Friedman (1957) and Hall (1978) in China. Using annual time-series, Chow (1985) obtained empirical evidence in favor of the PIH for the period 1952 to 1982 . Chow (2010) then updated the data for the period 1978 to 2006 and reached the same conclusion with Chow (1985). Using the 
data for the period 1978 to 2009 , that is, adding the period of the great global recession of 2008-9 into the data set of Chow (2010), Chow (2011) found a weak but supporting evidence for the PIH in China. Chow (2016) recently considered the data set for 1952 to 2013 and again obtained evidence in favor of the PIH. Therefore, he recently extended his empirical findings of 1985, 2010 and 2011 by covering longer periods. All these findings suggest that the consumption-income ratio is a meanreverting process in the Chinese economy; and therefore, its change is predictable. Mean-reversion in the consumption-income ratio means that policy shocks temporarily affect the consumption and saving behaviors of Chinese households. However, these studies neglected the role of nonlinearity in the consumption-ratio in China and also used the data for the national level. The current study found a significant nonlinearity and identified several provincial clusters for consumptionincome ratio, and the findings are somehow in line with the previous papers of Gregory C. Chow. Furthermore, the current evidence with a new methodology can provide useful information for the Chinese monetary authorities and policy makers.

Similarly, understanding the inflation path is important for monetary policy implications in China (Mehrotra et al., 2010). Understanding the inflation path is not only important for macroeconomic variables (e.g., real wage and input prices) in the domestic economy, but it is also related to the real value of the exchange rate that can affect other economies in the region, trading patterns in particular. However, an inadequate number of researches have investigated the inflation dynamics in China using nonlinear models. For instance, Chow (1987) and Chow and Wang (2010) focused on the explanation of inflation in China. Using annual data from 1952 to 2008, Chow and Wang (2010) found that there is no regime shift (constant parameters) in the Chinese inflation, despite the substantial changes in institutions 
after 1979. They used the ECM and observed that the lagged inflation rate, the growth rate of the ratio of money supply to output, and an error correction term are the main determinants of the Chinese inflation over the period under study. However, Zhang (2011,2013a) and Zhang and Clovis (2010) found significant structural breaks for the inflation dynamics in China, but these studies also used the linear models. With the use of a smooth transition error correction (STEC) model, Zhang (2013b) replicated the empirical analysis of Chow and Wang (2010) and found a significant regime-switching behavior of inflation; and thus, the evidence was in contrast to the results of Chow and Wang (2010). In a nutshell, another stylized fact for the Chinese provinces is the nonlinear behavior matters for obtaining statistically empirical evidence. ${ }^{1}$ That is why the econometric methodology of the current paper was designed to capture potential nonlinearity in inflation and other macroeconomic indicators in the analysis.

To the best of the authors' knowledge, this paper is the first to use retail inflation rates in the literature of club convergence clustering. Indeed, this issue offers important policy implications in the Chinese provinces. For instance, Chinese policy makers can implement price adjustment and control measures, and retailers in some regions can face temporary price ceilings. This could be an important policy tool for the central government, since the inflation risks in food and dairy products could create serious nutrition problems in some provinces as a result of the overpopulation in China.

The current study has identified several provincial clusters not only for the real GDP per capita, but also for the consumption-income ratio, retail inflation rate, and consumer inflation rate in 31 Chinese provinces for the period 1952 to 2013 . The

\footnotetext{
${ }^{1}$ There are also several studies to analyze the dynamics of regional inflation (prices) in other Asian countries, e.g., see Chow (2012) for Taiwan; Das and Bhattacharya (2008) for India; Nagayasu (2011) for Japan; Tillmann (2013) for (South) Korea.
} 
main contribution of this paper to the existing literature is that club convergence approach is not only implemented for the per capita income, but also for the $\mathrm{C} / \mathrm{Y}$ ratio and inflation dynamics. This evidence will enable local and central planners to select appropriate growth promotion, savings and price adjustment strategies for different groups of provinces. The results of the paper can also provide useful information to the local and central government to deal with increasing provincial inequality in different variables.

The rest of the paper is organized as follows: Section 2 explains the data and econometric methodology; Section 3 provides the empirical results and discusses the potential implications; Section 4 provides the conclusion.

\section{Data and Econometric Methodology}

\subsection{Data}

Investigation of provincial potential clusters for the per capita (real) GDP, consumption-income ratio $(\mathrm{C} / \mathrm{Y})$, retail price inflation $(\mathrm{RPI})$ and consumer price inflation (CPI) rates was carried out in this paper. This paper focused on the period from 1952 to 2013 in 31 Chinese provinces. Related data were obtained from the database of the China Yearly Provincial Macro-economy Statistics in 2016. The frequency of the data is yearly. A summary of the descriptive statistics of related variables is provided in Table 1.

[Insert Table 1 around here]

The per capita GDP level is also presented in Table 2. Table 2 shows the preliminary statistics of the average real GDP per capita (Yuan) and the share in total for different source markets (provinces).

[Insert Table 2 around here] 
According to the data in Table 2, the Chinese real GDP per capita greatly depends on four major cities/provinces: Beijing, Shanghai, Tianjin and Zhejiang. It is interesting to note that provinces with the highest initial GDP per capita grow much slower. This stylized fact in the Chinese regions is in line with the findings of Lau (2010).

\subsection{Econometric Methodology}

Phillips and Sul $(2007,2009)$ proposed a new methodological approach for testing convergence and identifying convergence clubs. The method uses a nonlinear timevarying factor model that captures the nonlinear transition mechanisms. One advantage of the methodology is that it does not require the assumptions of stationary series or existence of common factors in the data generating process. Another unique feature of the approach of Phillips and Sul (2007) is that it allows individual heterogeneity of source markets (regions)within a panel. Therefore, the test methodology allows for transitional dynamics of the Chinese provinces to be different in convergence testing within a panel, even though some particular source markets are initially in a state of transition or near steady state equilibrium. Since the growth rate for the individual provinces takes a wide range of values over the period 1952-2013, and possibly have different convergence paths, this methodological approach is very appropriate to test for the convergence of Chinese provinces. The goal of the present study was to identify the convergence clubs in the Chinese provinces using the following empirical approach.

\subsubsection{Relative Transition Paths}


The variable $X_{i t}$ denotes the variable of interest for province $i$ at time $t$, where $\mathrm{i}=1,2, \ldots, \mathrm{N} ; \mathrm{t}=1,2, \ldots, \mathrm{T}$. Following Phillips and Sul (2007), the variable can be decomposed into two components: the common components of cross-sectional dependence in a panel, $\mathrm{g}_{\mathrm{it}}$, and transitory components, $\mathrm{a}_{\mathrm{it}}$, as follows:

$$
X_{i t}=g_{i t}+a_{i t}
$$

Phillips and Sul (2007) reformulated Eq. (1) as common and idiosyncratic components were separated, and the model took a nonlinear form as follows:

$$
\mathrm{X}_{\mathrm{it}}=\left(\frac{\mathrm{g}_{\mathrm{it}}+\mathrm{a}_{\mathrm{it}}}{\mu_{\mathrm{t}}}\right) \mu_{t}=\delta_{\mathrm{it}} \mu_{\mathrm{t}} \quad \text { for } \quad \text { all } \quad i \quad \text { and } \quad \mathrm{t} \text {, }
$$

In Eq. (2), $\mu_{\mathrm{t}}$ is a common component and $\delta_{\mathrm{it}}$ is a time varying idiosyncratic element. That is, $\delta_{\text {it }}$ measures the relative distance between the common trend component $\mu_{t}$ and a source market's individual value of $X_{i t}$ at time $t$ (Eq. 2). In the scenario of the Chinese real GDP per capita for example, $\mu_{t}$ stands for a common real GDP per capita trend in the entire 31 provinces, while $\delta_{\text {it }}$ depicts a relative share of a specific province's real GDP per capita in common provincial trend in the whole economy. The main procedure in the convergence test of Phillips and Sul (2007) is to calculate the time-varying loadings $\delta_{\text {it }}$, such that, it can be used to determine the club convergence, if the loadings converge. Next, Phillips and Sul $(2007,2009)$ defined the transition coefficient as $h_{i t}$ and extracted the time-varying factor loadings $\delta_{\text {it }}$ as follows:

$$
\mathrm{h}_{\mathrm{it}}=\frac{\mathrm{X}_{\mathrm{it}}}{\frac{1}{\mathrm{~N}} \sum_{\mathrm{i}=1}^{\mathrm{N}} \mathrm{X}_{\mathrm{it}}}=\frac{\delta_{\mathrm{it}} \mu_{\mathrm{t}}}{\frac{1}{\mathrm{~N}} \sum_{\mathrm{i}=1}^{\mathrm{N}} \delta_{\mathrm{it}} \mu_{\mathrm{t}}}=\frac{\delta_{\mathrm{it}}}{\frac{1}{\mathrm{~N}} \sum_{\mathrm{i}=1}^{\mathrm{N}} \delta_{\mathrm{it}}}
$$


Where, $\mathrm{h}_{\mathrm{it}}$ is the transition parameter that measures $\delta_{\text {it }}$ in relation to the panel average at time $t$ and therefore, it describes the transition path for source market irelative to the panel average. Data for all variables adapted Hodrick and Prescott's (1997) filter with the value of Lambda set to 1200 for yearly data, to remove the cyclical trend from the original data. The filtered transition parameter coefficients were denoted as $\hat{h}_{i t}$, while the extracted time trend was denoted as $\hat{X}_{i t}$.

The most important part of the club convergence test is to construct the crosssectional variance ratio $\frac{\mathrm{H}_{1}}{\mathrm{H}_{\mathrm{t}}}$ where:

$$
\mathrm{H}_{\mathrm{t}}=\frac{1}{\mathrm{~N}} \sum_{\mathrm{i}=1}^{\mathrm{N}}\left(\hat{\mathrm{h}}_{\mathrm{it}}-1\right)^{2}
$$

Phillips and Sul (2007) proved that the transition distance $\mathrm{H}_{\mathrm{t}}$ has a limiting form, as follows:

$$
\mathrm{H}_{\mathrm{t}} \sim \frac{A}{L(t)^{2} t^{2 \alpha}} \text { as } t \rightarrow \infty
$$

Where, $A$ is a positive constant, $L(t)$ is a function of $\mathrm{t}$ and $\alpha$ denotes the convergence speed. To test for the null hypothesis of convergence, Phillips and Sul (2007) performed $\log t$ regressions such that, the null hypothesis of convergence was:

$\mathrm{H}_{0}: \delta_{\mathrm{i}}=\delta$ and $\alpha \geq 0$ and against the alternative $\mathrm{H}_{1}: \delta_{\mathrm{i}} \neq \delta$ for all $\mathrm{i}$ or $\alpha<0$.

\subsubsection{The log t Regression}

Following Phillips and Sul $(2007,2009)$ and Yifeng (2008), the following Ordinary Least Squares (OLS) regression was performed: 


$$
\log \left(\frac{\mathrm{H}_{1}}{\mathrm{H}_{\mathrm{t}}}\right)-2 \log \mathrm{L}(\mathrm{t})=\hat{\mathrm{a}}+\hat{\mathrm{b}} \log \mathrm{t}+\hat{\mathrm{c}}(\log \mathrm{t})^{2}+\hat{\mathrm{u}}_{\mathrm{t}}
$$

(6)

Where $L(t)=\log (t+1)$ and the fitted coefficient of $\log t$ is $\hat{b}=2 \widehat{\alpha}$, where and $\widehat{\alpha}$ is the estimate of $\alpha$ in the null hypothesis. The squares of log t were added to increase the power, that is, to capture the nonlinearities in the best way. To take into account the impact of initial conditions on the test, the empirical regression was run after a fraction of the sample was removed. The data for this regression starts at some point $t=[r T]$ with $r>0$. Phillips and Sul (2007) recommended $r=0.3$. For inference purpose, to employ a one-sided t test of null $\alpha \geq 0$ by using the estimate of $\hat{b}$, the standard errors of the estimates are calculated using a heteroskedasticity and autocorrelation consistent (HAC) estimator for the longrun variance of the residuals; therefore, the test statistic $t_{\widehat{b}}$ is normally distributed. The decision rule for the null hypothesis of convergence is rejected if $t_{\widehat{b}}<-1.645$ (Yifeng, 2008).

\subsubsection{Club Convergence Algorithm}

Phillips and Sul (2007) also argued that a strict rejection of the null of global convergence may not necessarily rule out the existence of sub-group convergence within the panel and a club convergence algorithm was developed to detect units of clusters. Following this procedure, the present paper will bring new information on the convergence process within the 31 provinces in China by revealing whether or not, clusters of convergence are present in the sample period. This examination of club convergence is important because the relationship within the clusters could be further investigated based on members' economic or structural characteristics within 
the club. The clustering algorithm is based on repeated log t regressions, and it contains four main steps, as described below.

Step 1 (Ordering): Order the member (that is, the $\mathrm{X}_{\mathrm{it}}$ series) in the panel according to the last observation.

Step 2 (Core Group Formation): Calculate the convergence t-statistic $t_{\widehat{b}}(k)$ for each panel unit $(k)$. A core group is formed by selecting the first $\mathrm{k}$ highest panel members (Step 1) to form the subgroup $\mathrm{G}_{\mathrm{k}}$ for some $\mathrm{N}>k \geq 2$ and the core group size $\mathrm{k}^{*}$ is chosen by maximizing $\mathrm{t}_{\widehat{\mathrm{b}}}(\mathrm{k})$ under the condition that $\min \left\{\mathrm{t}_{\widehat{\mathrm{b}}}(\mathrm{k})\right\}>-1.65$.

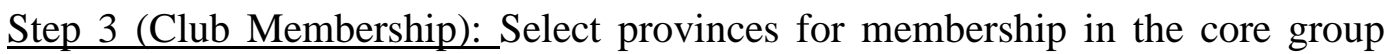
(Step 2) by adding each remaining province separately to the core group and the $\log$ $t$ test is run. The new province (member) will be included, if the associated t-statistic is greater than zero (conservative choice). The convergence criterion is checked for the club as usual.

Step 4 (Recursion and Stopping): The log t test is run on the group of unselected provinces in Step 3. If this set of provinces converge, then the second club is formed. Otherwise, repeat Steps 1 to 3 to reveal some sub-convergent clusters. If no subgroups are found (Step 2), then these provinces show a divergent behavior.

\section{Empirical Results, Discussion and Policy Implications}

\subsection{Empirical Results}

In Table 3, the above algorithm was used to identify any clusters for the real GDP per capita into distinct convergence clubs. The panel convergence test results for the real GDP per capita in logarithmic form (lnx), real GDP per capita growth (year-toyear) (Gx) and real GDP per capita growth relative to its initial period $(\lg x)$ are 
presented in Table 3. Thus, the clusters can be identified both in per capita income and economic growth.

\section{[Insert Table 3 around here]}

With regards to the results of the convergence test of real GDP per capita logarithmic form $(\ln x)$, the $\log t$ regression with the first club consisting of seven provinces gives a t statistic of 2.438 , and the null hypothesis of convergence cannot be rejected. Hence, the first convergence club includes seven provinces. ${ }^{2}$ The second club includes two provinces $(\mathrm{t}$ statistic $=-1.516)$, the third club includes five provinces $(\mathrm{t}$ statistic $=-1.630)$ and the fourth club includes eight provinces $(\mathrm{t}$ statistic $=0.629)$. The final club includes three provinces $(\mathrm{t}$ statistic $=0.681)$.

[Insert Figure 1 around here]

For the convergence test of growth in real GDP per capita $(\mathrm{Gx})$, the $\log \mathrm{t}$ regression with the only convergent club consisting of 25 provinces gave a t statistic of 1.126 , and the null hypothesis of convergence cannot be rejected. Hence, the first convergence club includes 25 provinces. For the remaining six provinces, the $\log \mathrm{t}$ test rejects the null of convergence with a $t$ statistic of -4.214 . Therefore, the nonconverging provinces consist of six provinces (Table 4). It is interesting to further examine the reasons why these six provinces (Anhui, Guizhou, Tibet, Gansu, Qinghai and Ningxia) cannot converge with the rest of the economy, and local and central planners have to select appropriate strategies for these six provinces to converge with the rest of the economy, if tackling income equality is an important policy of the central government.

[Insert Figure 2 around here]

${ }^{2}$ See Table 2 for which province is tagged with which number. 
With regards to the results of the convergence test of the real GDP per capita growth relative to its initial period $(\lg x)$, the $\log t$ regression with the first club consisting of six provinces gave a $t$ statistic of -4.214 , and the null hypothesis of convergence can be rejected. Hence, the first convergence club includes six provinces. The second club has four provinces $(\mathrm{t}$ statistic $=0.431)$, the third club has three provinces $(\mathrm{t}$ statistic $=-1.583)$, and the fourth club has18 provinces $(\mathrm{t}$ statistic $=$ 16.65). These empirical findings are somewhat in line with the previous results of Herrerias and Ordonez (2012) and Herrerias and Ordonez Monfort (2015).

[Insert Figure 3 around here]

Table 4 identifies any clusters for the consumption to income ratio $(\mathrm{C} / \mathrm{Y})$, the retail inflation rate $(1984=100)$, and the consumer inflation rate $(1984=100)$. With regards to the convergence test of consumption to income ratio $(\mathrm{C} / \mathrm{Y})$, the $\log \mathrm{t}$ regression with the first club consisting of nine provinces gave a t statistic of 0.584 , and the null hypothesis of convergence cannot be rejected. Hence, the first convergence club includes nine source markets. The second club has two provinces $(\mathrm{t}$ statistic $=-1.512)$, the third club has five provinces $(\mathrm{t}$ statistic $=7.212)$, and the last club has 14 provinces $(\mathrm{t}$ statistic $=2.074)$.

[Insert Table 4 around here]

[Insert Figure 4 around here]

With regards to the convergence test of the retail inflation rate, the log t regression with the first club which consists of 17 provinces gave a t statistic of 0.102 , and the null hypothesis of convergence cannot be rejected. Hence, the first convergence club includes 17 source markets. The second club includes five provinces $(\mathrm{t}$ statistic $=-$ 1.575), the third club includes two provinces ( $\mathrm{t}$ statistic $=-0.886)$, and the last club includes four provinces $(\mathrm{t}$ statistic $=-1.364)$. 
[Insert Figure 5 around here]

Finally, the convergence test of consumer inflation rate was examined, the $\log \mathrm{t}$ regression with the first club which consists of 10 provinces gave a t statistic of 1.226, and the null hypothesis of convergence cannot be rejected. Hence, the first convergence club includes 10 source markets. The second club includes 18 provinces $(\mathrm{t}$ statistic $=0.443)$.

[Insert Figure 6 around here]

\subsection{Discussion and Policy Implications}

First, it was found that all series of the original data contain significant nonlinear components $^{3}$ and the Chinese per capita GDP heavily depends on four major provinces: Beijing, Shanghai, Tianjin and Zhejiang (Table 2).

Second, it was observed that there are five significant clusters for the income per capita in China. Moreover, the real GDP per capita growth rates (year-to-year) have just one cluster, and the cluster covers 25 provinces; however, Anhui, Guizhou, Tibet, Gansu, Qinghai and Ningxia are not in this cluster. Therefore, the results provide useful information for local authorities and the central government to deal with increasing provincial inequality, especially in these six regions. Similarly, the real GDP per capita growth rates (growth-to-initial period) also have four clusters in the Chinese provinces over the period under study. These results will enable local and central planners to select appropriate growth promotion strategies for four different groups of provinces (Table 3). Since China has significant demand for commodities,

\footnotetext{
${ }^{3}$ The Phillips and Sul (2007) method begins with a convergence club test for the entire sample of units; in the current case, 31 Chinese provinces. Then, if we reject this level of convergence, we cannot move to club convergence. We did not report these first tests to save space, but they are available upon request.
} 
its economic growth rate is not only important to the domestic economy, but also to its trading-partners, which are commodity-exporters in particular.

The difference in convergence pattern between GDP levels and GDP growth can be better understood from the perspective provided by the Solow growth model, particularly the notion of conditional convergence to balanced growth paths. Crossprovince difference in the fundamentals that determine income level at balanced growth paths (institution quality, investment rates, and so on) may cause a persistent component of cross-province income differences. That explains the existence of 5 significant provincial clusters in income level within China. By contrast, Chinese provinces might be quite similar in the forces that determine growth rate at balanced growth path (diffusion of knowledge and technological progress). That explains why the vast majority of Chinese provinces are shown to be included into one single convergent club in the growth rate of income. Note that a total of 25 provinces in China are shown to be included into one single convergent club for the test of yearto-year growth rate and a total of 18 provinces for the test of relative-to-initial-period growth rate.

Third, it was found that there are four significant clusters for the consumptionincome ratio in China. These results will enable local and central planners to implement appropriate savings policies for four different groups of provinces. Indeed, China has an export-oriented growth strategy (export-led growth model) (Gozgor, 2014), and it has a significant surplus in the external balance; thus, surplus in savings (Deer and Song, 2012). The Chinese economy has also experienced a rapid economic growth from the early 1980 s to the early 2010 s, but the pace of economic growth has declined in the mid-2010s (Banister et al., 2012). It can be suggested that the key policy implication in the Chinese economy to sustain economic growth is to 
transform the economy from the "export-led growth" or "domestic investment-led growth" to the "domestic consumption-led growth". Therefore, the results of this study also show that there are four groups of provinces for implementation of a possible "consumption-led growth" strategy in the Chinese economy.

Fourth, it was observed that there are four significant clusters for the retail inflation rates and two significant clusters for the consumer inflation rates in China (Table 4). These results will enable local and central planners to implement price adjustment policies for different groups of provinces. For instance, if the economic growth rate of the Chinese economy slows down, this will destroy jobs-openings and create unemployment problems in the economy. Given that China is a crowded country, this issue can result in political uncertainty and civil disturbance. The key policy implication here is to call the validity of the New Keynesian Phillips Curve (NKPC) into question. Indeed, if the NKPC is valid in the Chinese economy, it will provide a trade-off between inflation and unemployment rates (Zhang, 2013a). Unfortunately, unemployment data are unavailable for the Chinese economy at the regional level to analyze the validity of the NKPC. Nevertheless, the empirical findings of the present study show that price adjustment policies can be successful in some provinces, that is, the different groups of price clusters. These results are also in line with the previous findings. For instance, Westerlund et al. (2010) explained the results of divergence in Chinese provinces by Pedroni and Yao (2006). Their results are particularly important because of the disparities between groups of provinces, which is directly related to the current paper. In the current study, there are different provinces in the different clubs. Following the findings of these papers, it can also be concluded that having different members is not a drawback of the econometric methodology. 
For future research it is important to examine the key drivers of club convergence. Provinces are considered to be heterogeneous in terms of market structure, local governmental politics, and levels of development, the culture of doing business, dialects, consumer preferences, and international exposure. The first strand of argument emphasizes the important role of market structure. Fan and Wei (2006) argues that a relatively high competitive market could lead to a more frequent price convergent pattern across provinces (Fan and Wei, 2006). Therefore market structure is the main driver of club convergence, and this implies provinces with successful transition program to market economy will exhibit convergence pattern (Young, 2000).

Another strand of argument concerns the unique political institutional arrangement in China where the Regionally Decentralised Authoritarian System links provincial economic performance to the career promotion of local officials $(\mathrm{Xu}$, 2011). Therefore we expect provinces that accept and implement centralized policies to show club convergence.

The third strand of argument concerns the heterogeneous economic development across regions. The beta-convergence hypothesis that derived from the neoclassical growth model implies that that if a poor province grows faster than the rich one, the poor province will eventually catch up and to converge towards a long-run steady state (Furceri, 2005). Therefore provinces with similar level of initial regional economic development may have similar long run steady state and shows club convergence, provided that provinces have similar structural characteristics.

\section{Conclusion}


In this study, the convergence clustering in 31 Chinese provinces regarding several important economic indicators over the period 1952-2013, was empirically investigated. Using the club convergence and clustering procedure of Phillips and Sul (2007), several provincial clusters were identified for the per capita (real) GDP, consumption-income ratio, retail price, and consumer price inflation rates. Since China has undergone a significant transformation over the period under consideration, the econometric methodology of the paper is the most suitable technique to capture the time-varying effects and heterogeneity among provinces. The results of this study show that the Chinese regions have converged into clubs in all macroeconomic indicators.

The empirical findings are as follows. First, it was found that all series of the original data contain a significant nonlinear component. Second, it was found that there are five significant clusters for the income per capita in China. Moreover, the real GDP per capita growth rates (year-to-year) have only one cluster and the cluster covers 25 provinces. Similarly, the real GDP per capita growth rates (growth-toinitial period) also have four clusters in the Chinese provinces over the period under study. Third, it was observed that there are four significant clusters for the consumption income ratio. Fourth, it was found that there are four significant clusters for the retail inflation rates, and there are two significant clusters for the consumer inflation rates in China. These results will enable local and central planners to implement economic growth, savings and price adjustment policies for different groups of provinces.

Future studies on this subject can focus on other developing countries by using the club convergence and clustering procedure of Phillips and Sul (2007 and 2009), 
which have available long-run data on the income, price level, consumption and unemployment rate at the regional (provincial) level.

\section{References}

Banister, J., Bloom, D.E., \& Rosenberg, L. (2012). Population aging and economic growth in China. M. Aoki \& J. Wu (Eds.), the Chinese Economy: A New Transition. (pp. 114-150), Palgrave Macmillan: New York, NY.

Cheong, T.S., \& Wu, Y. (2013). Regional disparity, transitional dynamics and convergence in China. Journal of Asian Economics, 29, 1-14.

Cheong, T.S., \& Wu, Y. (2014). The impacts of structural transformation and industrial upgrading on regional inequality in China. China Economic Review, 31, $339-350$.

Chow, G.C. (1985). A model of Chinese national income determination. Journal of Political Economy, 93 (4), 782-792.

Chow, G.C. (1987). Money and price level determination in China. Journal of Comparative Economics, 11 (3), 319-333.

Chow, G.C. (2010). Note on a model of Chinese national income determination. Economics Letters, 106 (3), 195-196.

Chow, G.C. (2011). Lessons from studying a simple macroeconomic model for China. Economics Letters, 112 (3), 233-235.

Chow, G.C. (2012). A model of inflation in Taiwan. Economics Letters, 117 (2), 464-466.

Chow, G.C. (2016). Important laws governing China's macro-economy. Journal of Comparative Economics, 44 (2), 289-294. 
Chow, G.C., \& Wang. P. (2010). The empirics of inflation in China. Economics Letters, 109 (1), 28-30.

Das, S., \& Bhattacharya, K. (2008). Price convergence across regions in India. Empirical Economics, 34 (2), 299-313.

Deer, L.D., \& Song, L. (2012). China's approach to rebalancing: A conceptual and policy framework. China \& World Economy, 20 (1), 1-26.

Fan, C.S. and Wei, X. (2006), The law of one price: Evidence from the transitional economy of China, The Review of Economics and Statistics, 88(4): 682-97.

Friedman, M. (1957). A Theory of the Consumption Function. Princeton University Press: Princeton, NJ.

Furceri, D. (2005). $\beta$ and $\sigma$-convergence: A mathematical relation of causality. Economics Letters, 89(2), 212-215.

Gozgor, G. (2014). Aggregated and disaggregated import demand in China: An empirical study. Economic Modelling, 43, 1-8.

Hall, R.E. (1978). Stochastic implications of the life cycle-Permanent Income Hypothesis: theory and evidence. Journal of Political Economy, 86 (6), 971-987.

Herrerias, M.J., \& Ordonez Monfort, J. (2015). Testing stochastic convergence across Chinese provinces, 1952-2008. Regional Studies, 49 (4), 485-501.

Herrerias, M.J., \& Ordonez, J. (2012). New evidence on the role of regional clusters and convergence in China (1952-2008).China Economic Review, 23 (4), 11201133.

Herrerias, M.J., Orts, V., \& Tortosa-Ausina, E. (2011). Weighted convergence and regional clusters across China. Papers in Regional Science, 90 (4), 703-734.

Ho, C-Y., \& Li, D. (2010). Spatial dependence and divergence across Chinese cities. Review of Development Economics, 14 (2), 386-403. 
Hodrick, R.J., \& Prescott, E.C. (1997). Postwar U.S. business cycles: An empirical investigation. Journal of Money, Credit and Banking, 29 (1), 1-16.

Knight, J. (2014). Inequality in China: an overview. The World Bank Research Observer, 29 (1), 1-19.

Lau, C.K.M. (2010). New evidence about regional income divergence in China. China Economic Review, 21 (2), 293-309.

Lyhagen, J., \& Rickne, J. (2014). Income inequality between Chinese regions: Newfound harmony or continued discord?Empirical Economics, 47 (1), 93-110.

Mehrotra, A., Peltonen, T., \& Santos Rivera, A. (2010). Modelling inflation in China-A regional perspective. China Economic Review, 21 (2), 237-255.

Nagayasu, J. (2011). Heterogeneity and convergence of regional inflation (prices). Journal of Macroeconomics, 33 (4), 711-723.

Pedroni, P., \& Yao, J.Y. (2006). Regional income divergence in China. Journal of Asian Economics, 17 (2), 294-315.

Phillips, P.C.B., \& Sul, D. (2007). Transition modeling and econometric convergence tests. Econometrica, 75 (6), 1771-1855.

Phillips, P.C.B., \& Sul, D. (2009).Economic transition and growth. Journal of Applied Econometrics, 24 (7), 1153-1185.

Sakamoto, H., \& Islam, N. (2008). Convergence across Chinese provinces: An analysis using Markov transition matrix. China Economic Review, 19 (1), 66-79.

Tillmann. P. (2013). Inflation targeting and regional inflation persistence: Evidence from Korea. Pacific Economic Review, 18 (2), 147-161.

Westerlund, J., Edgerton, D.L., \& Opper, S. (2010). Why is Chinese regional output diverging? Journal of Asian Economics, 21 (4), 333-344. 
$\mathrm{Xu}, \mathrm{C}$. (2011), The fundamental institutions of China's reforms and development, Journal of Economic Literature, 49(4): 1076-151.

Yifeng, H. (2008). Economic convergence in transition economy of China: An empirical study with a nonlinear time-varying factor model. Economic Research Journal, 7, 39-51.

Young, A. (2000), The razor's edge: Distortions and incremental reform in the People's Republic of China, The Quarterly Journal of Economics, 115(4): 1091135.

Zhang, C. (2011). Inflation persistence, inflation expectations, and monetary policy in China. Economic Modelling, 28 (1-2), 622-629.

Zhang, C. (2013a). Inflation dynamics and an extended New Keynesian Phillips Curve for China. Emerging Markets Finance and Trade, 49 (5), 82-98.

Zhang, C., \& Clovis, J. (2010). China inflation dynamics: Persistence and policy regimes. Journal of Policy Modeling, 32 (3), 373-388.

Zhang, L. (2013b). Revisiting the empirics of inflation in China: A smooth transition error correction approach. Economics Letters, 119 (1), 68-71. 
Table 1

Descriptive Statistics for 31 China Regions (1952-2013).

\begin{tabular}{ccccc}
\hline Variables: & GDP per Capita & Consumption/Income & Consumer Price Index & Retail Price Index \\
\hline Mean & 23521.6 & 62.23 & 5.745 & 3.092 \\
Median & 889.3 & 61.84 & 1.367 & 1.200 \\
Maximum & 386875 & 115.8 & 65.38 & 46.20 \\
Minimum & 33.4 & 21.57 & -21.52 & -15.00 \\
Standard Deviation & 50916.4 & 14.82 & 11.74 & 6.074 \\
Observations & 1806 & 1751 & 1775 & 1803 \\
\hline
\end{tabular}


Table 2

Real GDP in the Chinese Provinces from 1952-2013 (Yuan)

\begin{tabular}{cccccccc}
\hline Code & Province & Average GDP & Share & Code & Province & Average GDP & Share \\
\hline 1 & Beijing & 58043.39 & 8.00 & 17 & Hubei & 17878.71 & 2.46 \\
2 & Tianjin & 42086.44 & 5.80 & 18 & Hunan & 17911.75 & 2.47 \\
3 & Hebei & 17848.40 & 2.46 & 19 & Guangdong & 30455.31 & 4.20 \\
4 & Shanxi & 16164.96 & 2.23 & 20 & Guangxi & 13386.30 & 1.84 \\
5 & Inner Mongolia & 25997.74 & 3.58 & 21 & Hainan & 33506.83 & 4.62 \\
6 & Liaoning & 26402.35 & 3.64 & 22 & Chongqing & 18106.48 & 2.50 \\
7 & Jilin & 20188.44 & 2.78 & 23 & Sichuan & 14271.75 & 1.97 \\
8 & Heilongjiang & 19729.86 & 2.72 & 24 & Guizhou & 8586.09 & 1.18 \\
9 & Shanghai & 57716.02 & 7.95 & 25 & Yunnan & 11649.89 & 1.61 \\
10 & Jiangsu & 33472.69 & 4.61 & 26 & Tibet & 18326.78 & 2.53 \\
11 & Zhejiang & 36472.44 & 5.03 & 27 & Shaanxi & 17899.72 & 2.47 \\
12 & Anhui & 18951.54 & 2.61 & 28 & Gansu & 16425.11 & 2.26 \\
13 & Fujian & 25795.11 & 3.55 & 29 & Qinghai & 18891.54 & 2.60 \\
14 & Jiangxi & 13265.64 & 1.83 & 30 & Ningxia & 18553.41 & 2.56 \\
15 & Shandong & 23403.12 & 3.22 & 31 & Xinjiang & 19251.14 & 2.65 \\
16 & Henan & 15051.63 & 2.07 & & & & \\
\hline
\end{tabular}


Table 3

Results of the Club Convergence Test for the Real GDP per Capita.

\begin{tabular}{|c|c|c|c|c|c|c|c|c|c|c|c|c|}
\hline Data & Clubs & & & & & & & & & & $b^{\wedge}$ & $\mathrm{t}$-statistic \\
\hline \multirow[t]{10}{*}{$\begin{array}{c}\text { Divergent: } \\
\text { Log Real GDP per Capita }\end{array}$} & (1) & & & & & & & & & & & \\
\hline & 1 & 2 & 5 & 7 & 9 & 10 & 11 & & & & 0.631 & 2.438 \\
\hline & (2) & & & & & & & & & & -2.961 & -1.516 \\
\hline & 3 & 4 & & & & & & & & & & \\
\hline & (3) & & & & & & & & & & -0.286 & -1.630 \\
\hline & 6 & 19 & 25 & 28 & 31 & & & & & & & \\
\hline & (4) & & & & & & & & & & & \\
\hline & 8 & 15 & 16 & 17 & 18 & 20 & 27 & & & & 0.186 & 0.629 \\
\hline & (5) & & & & & & & & & & 0.468 & 0.681 \\
\hline & 24 & 29 & 30 & & & & & & & & & \\
\hline \multirow[t]{4}{*}{$\begin{array}{l}\text { Real GDP per Capita Growth } \\
\text { (Year-to-year) }\end{array}$} & (1) & & & & & & & & & & 0.059 & 1.126 \\
\hline & 1 & 2 & 3 & 4 & 5 & 6 & 7 & 8 & 9 & 10 & & \\
\hline & 11 & 13 & 14 & 15 & 16 & 17 & 18 & 19 & 20 & 21 & & \\
\hline & 22 & 23 & 25 & 27 & 31 & & & & & & & \\
\hline \multirow[t]{8}{*}{$\begin{array}{l}\text { Real GDP per Capita Growth } \\
\text { (Relative to its Initial Period) }\end{array}$} & (1) & & & & & & & & & & -1.476 & -4.214 \\
\hline & $\begin{array}{l}12 \\
(2)\end{array}$ & 24 & 26 & 28 & 29 & 30 & & & & & 0.646 & 0.431 \\
\hline & 5 & 19 & 25 & 31 & & & & & & & & \\
\hline & (3) & & & & & & & & & & -1.084 & -1.583 \\
\hline & 2 & 13 & 14 & & & & & & & & & \\
\hline & (4) & & & & & & & & & & 3.911 & 16.65 \\
\hline & 1 & 3 & 4 & 6 & 7 & 8 & 9 & 10 & 11 & 15 & & \\
\hline & 16 & 17 & 18 & 20 & 21 & 22 & 23 & 27 & & & & \\
\hline
\end{tabular}


Table 4

Results of the Club Convergence Test for the C/Y, Retail-, and Consumer Inflation.

\begin{tabular}{|c|c|c|c|c|c|c|c|c|c|c|c|c|}
\hline Data & Clubs & & & & & & & & & & $b^{\wedge}$ & t-statistic \\
\hline \multirow[t]{9}{*}{$\mathrm{C} / \mathrm{Y}$} & (1) & & & & & & & & & & 0.266 & 0.584 \\
\hline & 2 & 5 & 8 & 10 & 16 & 22 & 28 & 29 & 30 & & & \\
\hline & (2) & & & & & & & & & & -3.991 & -1.512 \\
\hline & 14 & 15 & & & & & & & & & & \\
\hline & (3) & & & & & & & & & & 1.072 & 7.212 \\
\hline & 1 & 12 & 13 & 26 & 27 & & & & & & & \\
\hline & (4) & & & & & & & & & & 0.647 & 2.074 \\
\hline & 3 & 4 & 6 & 7 & 9 & 11 & 17 & 18 & 19 & 20 & & \\
\hline & 23 & 24 & 25 & 31 & & & & & & & & \\
\hline \multirow{9}{*}{$\begin{array}{l}\text { Retail Inflation Rate } \\
\quad(1984=100)\end{array}$} & (1) & & & & & & & & & & 0.133 & 0.102 \\
\hline & 1 & 2 & 3 & 4 & 5 & 6 & 7 & 8 & 16 & 21 & & \\
\hline & 22 & 23 & 25 & 27 & 28 & 29 & 31 & & & & & \\
\hline & (2) & & & & & & & & & & -1.972 & -1.575 \\
\hline & 9 & 10 & 11 & 12 & 13 & & & & & & & \\
\hline & (3) & & & & & & & & & & -1.788 & -0.886 \\
\hline & 14 & 15 & & & & & & & & & & \\
\hline & (4) & & & & & & & & & & -1.460 & -1.364 \\
\hline & 18 & 20 & 26 & 30 & & & & & & & & \\
\hline \multirow[t]{5}{*}{$\begin{array}{c}\text { Consumer Inflation Rate } \\
(1984=100)\end{array}$} & (1) & & & & & & & & & & -1.068 & -1.226 \\
\hline & 2 & 5 & 6 & 7 & 13 & 19 & 23 & 25 & 26 & 31 & & \\
\hline & (2) & & & & & & & & & & 0.770 & 0.443 \\
\hline & 1 & 3 & 4 & 8 & 9 & 10 & 11 & 14 & 15 & 16 & & \\
\hline & 17 & 18 & 20 & 21 & 22 & 24 & 28 & 28 & & & & \\
\hline
\end{tabular}




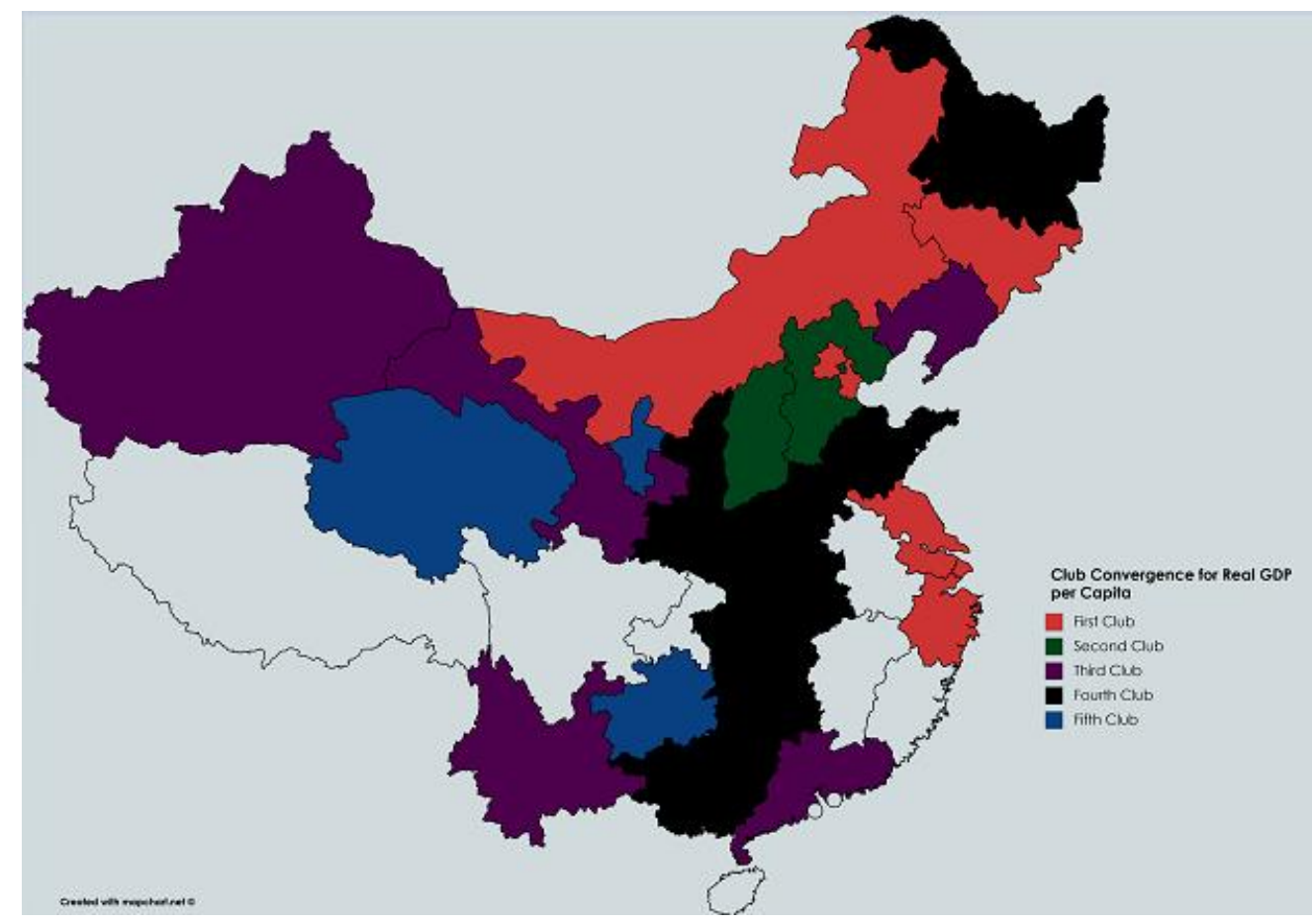

Figure 1.

Club Convergence for Real GDP per Capita

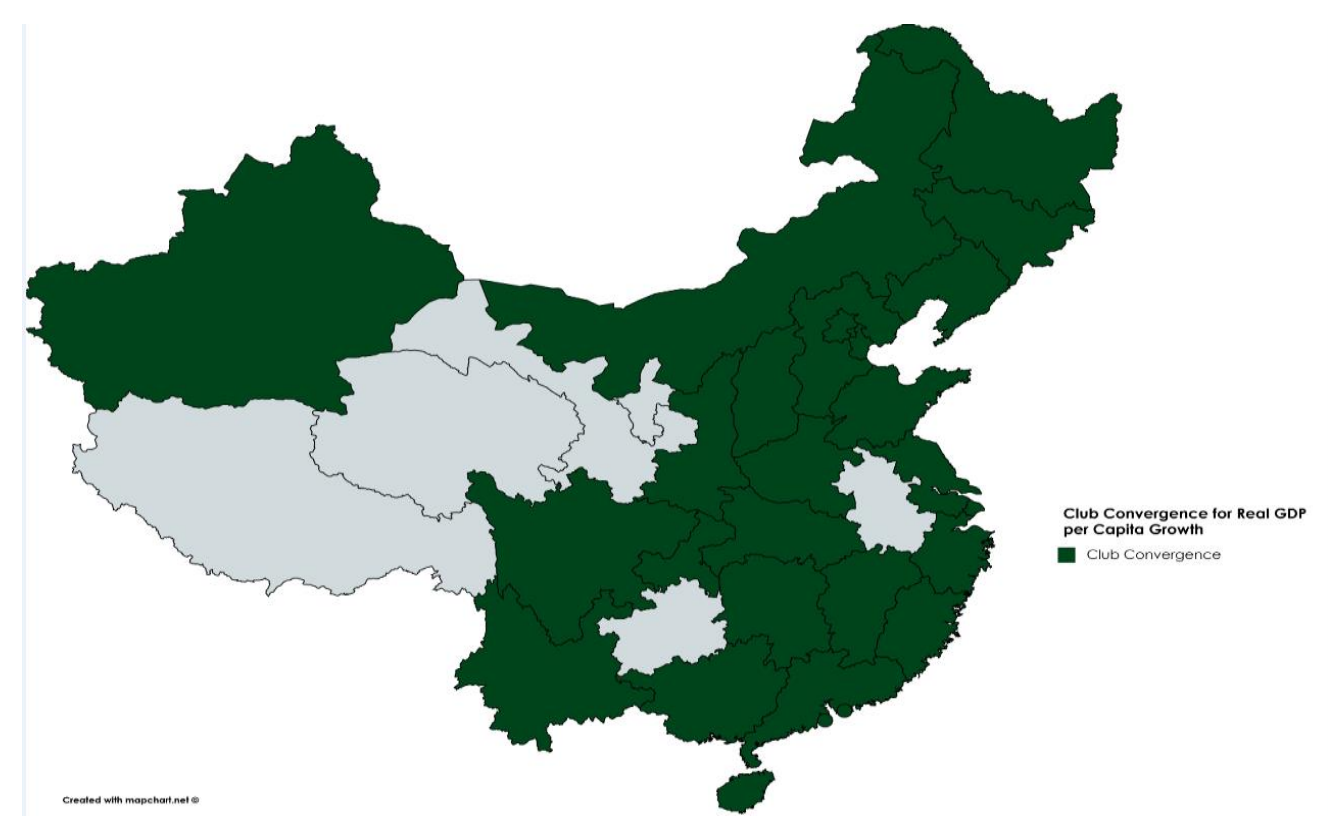


Figure 2.

Club Convergence for Real GDP per Capita Growth

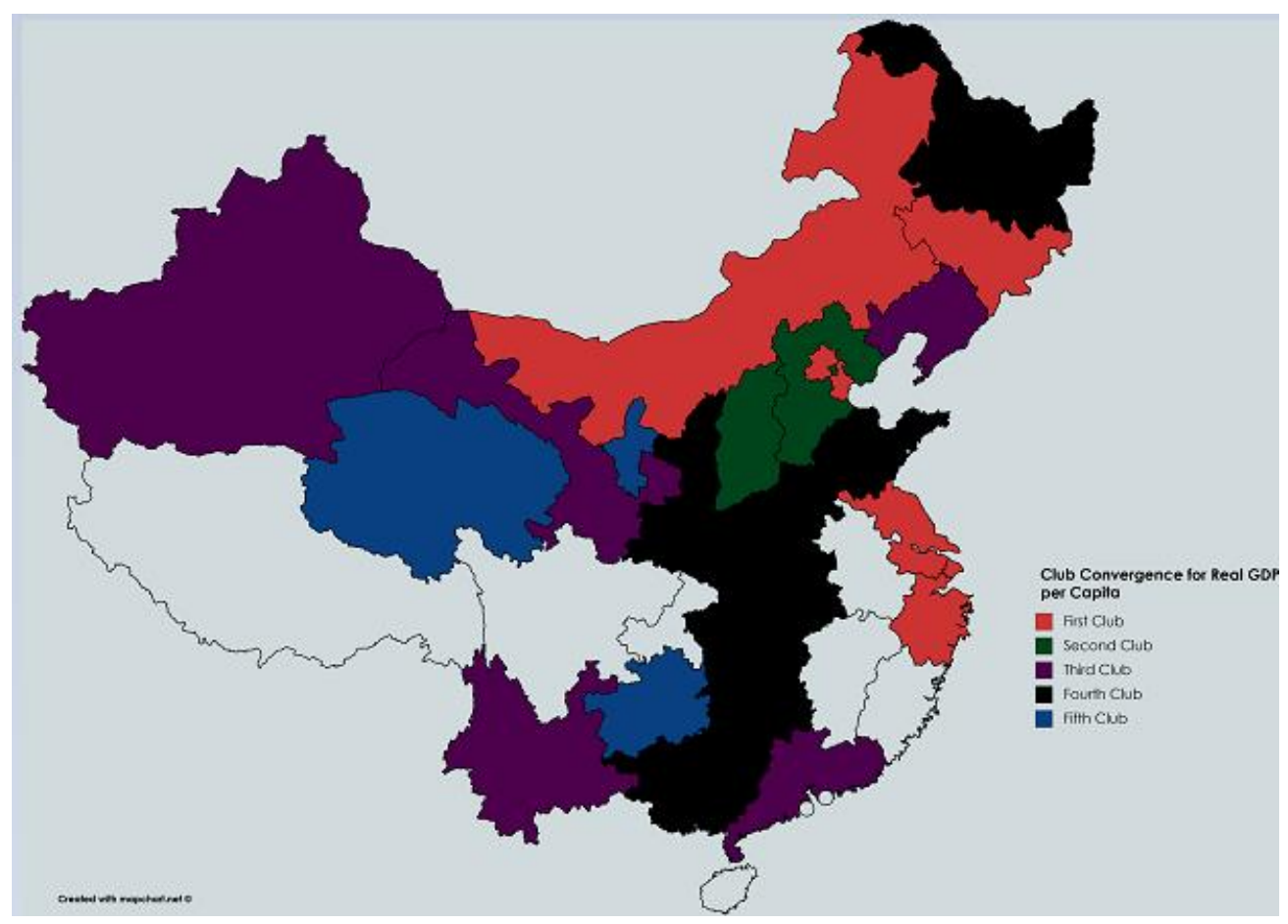

Figure 3.

Club Convergence for Real GDP per Capita Growth Relative to its Initial

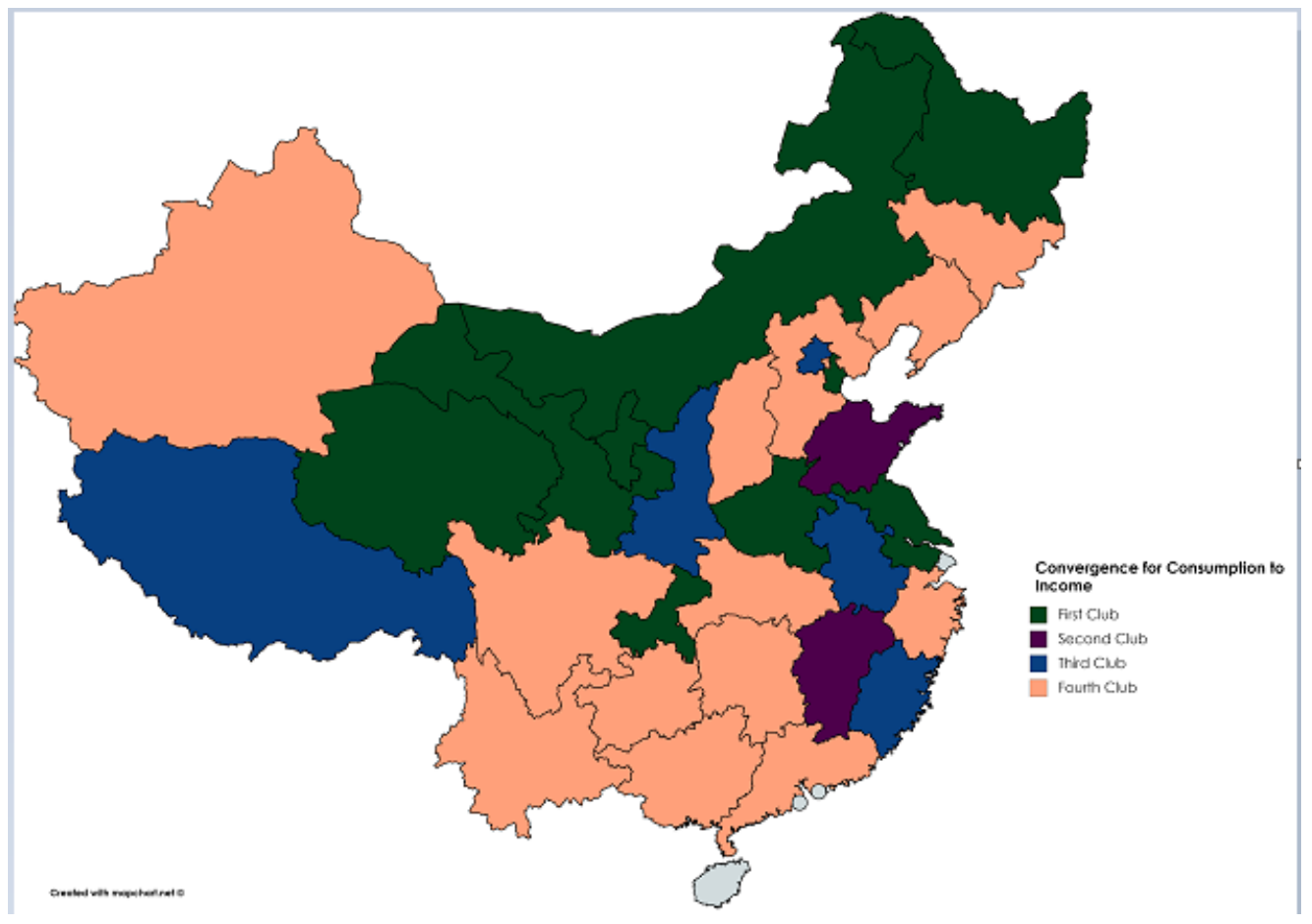


Figure 4.

Club Convergence for Consumption to Income

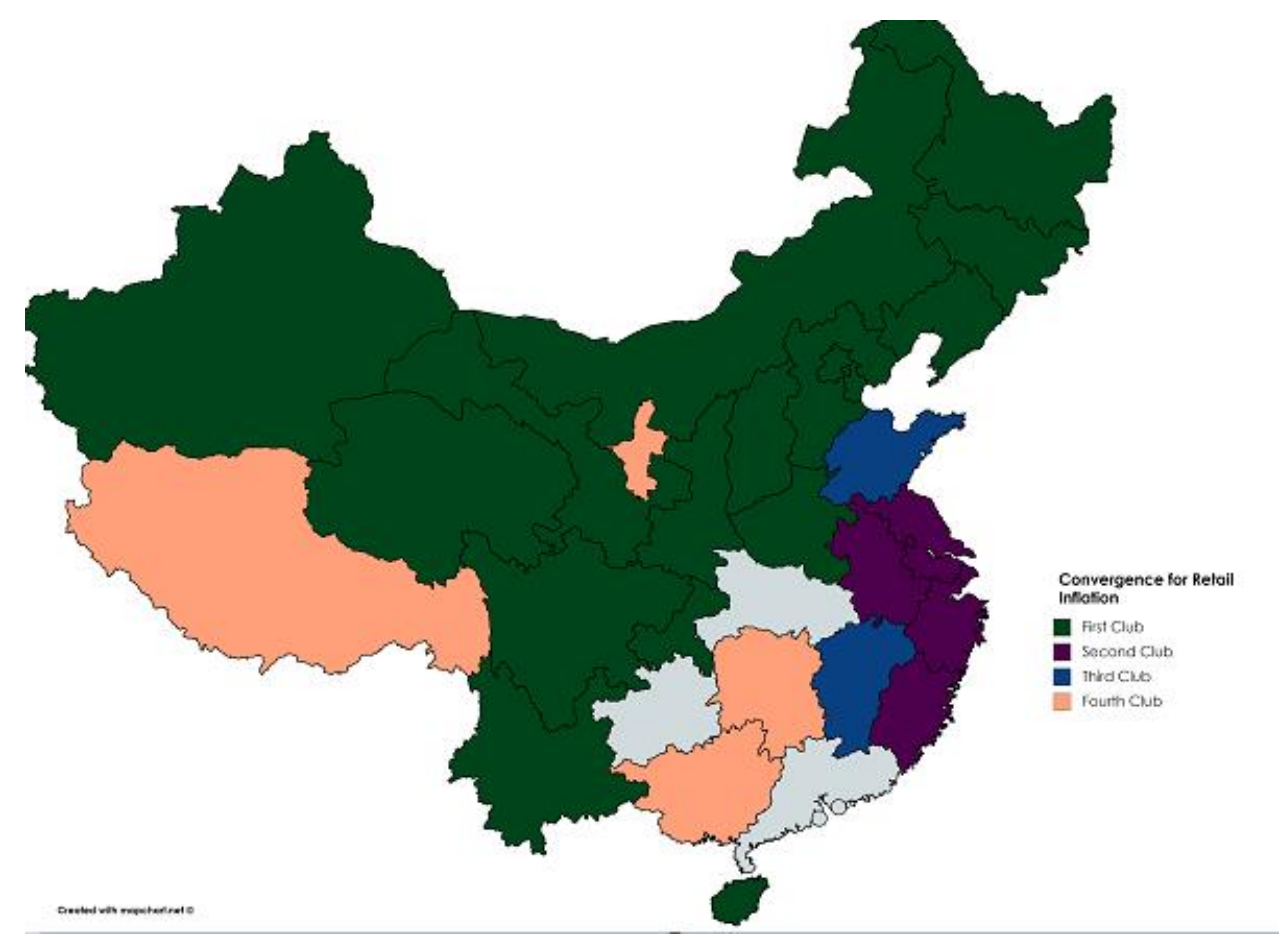

Figure 5.

Club Convergence for Consumption to Retail Inflation Rate 


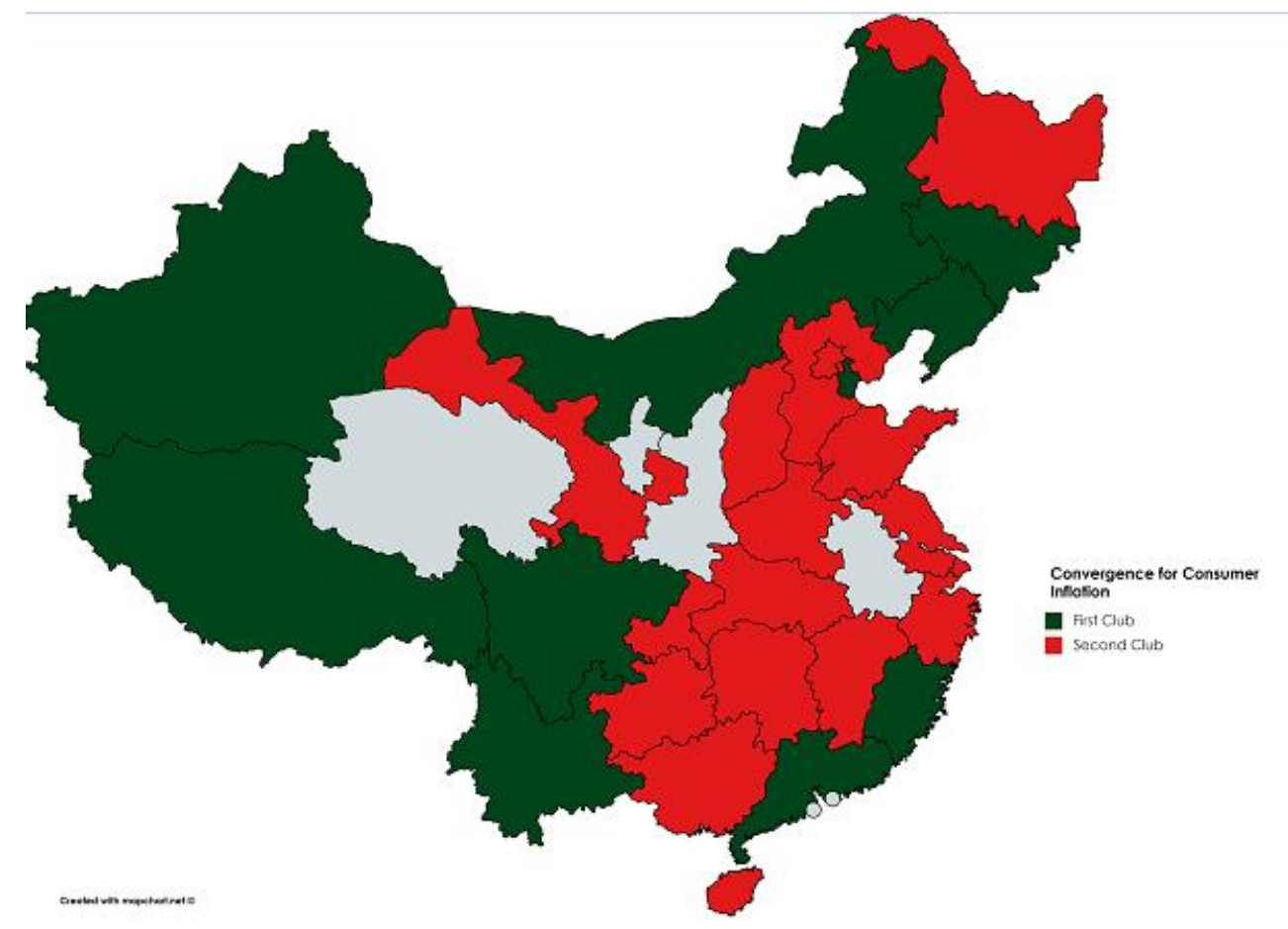

Figure 6.

Club Convergence for Consumption to Consumer Inflation Rate 